R. J. Learson: Gemeinsame Untersuchung über eine elektrophoretische Sehnellmethode zur Bestimmung der Fischart. II. Authentische Fleiseh-Standards. (Collaborative Study of a Rapid Electrophoretic Method for Fish Species Identification. II. Authentic Flesh Standards.) (Gloucester, Fish and Wildlife Service, Bureau of Commercial Fisheries.) J. Ass. off. analytic. Chem. 58, 7-9 (1970).

Nach der Celluloseacetat-methode konnten 11 Mitarbeiter die fraglichen Befunde mit $91 \%$ Sicherheit den richtigen Fischspezies zuordnen. Zum Vergleich dienten die hergestellten Standards.

H. Reichenbach-Klinke (München)

G. H. Houghtby und C. A. Kaysner: Das Vorkommen von Clostridium botulinum Typ E in Alaska-Lachs. (Incidence of Clostridium botulinum Type $\mathbf{E}$ in Alaskan Salmon.) (Seattle, Food and Drug Administration.) Appl. Microbiol. 18, 950-951 (1969).

Obwohl Ausbrüche von Botulismus im Zusammenhang mit Lachsprodukten in Alaska beobachtet wurden, wurde bisher darüber nicht berichtet. Diese Arbeit tut es und befaßt sich mit Feststellungen an Clostridium botulinum Typ $\mathrm{E}$ aus Küstengewässern und Flüssen Alaskas im Jahre 1968. - Aus den Kiemen der Lachse wurden öfter Clostridien isoliert als aus den Eingeweiden. Identifiziert wurden die Clostridien kulturell, aber auch durch Isolierung des Toxins. Die benutzten Nährböden werden angegeben auch aufgetretene Schwierigkeiten mit gewissen Nährböden bei differierenden pH-Werten. Am häufigsten kamen Clostridien bei Lachsen, die in Flüssen gefangen worden waren, vor. Die einzelnen Fangplätze werden aufgezählt. 4 Lachsarten wurden in die Untersuchungen einbezogen. 1 Tabelle, 8 Literaturangaben.

H. Wittfogel (Bremervörde)

\title{
Fischerzeugnisse
}

T. C. Yu, M. K. Landers und R. O. Sinuhuber: Verlängerung des Frischezustandes bei der Lagerung von wiedergefrorenen Silberlachs-Steaks. (Storage life extension of refrozen silver salmon steaks.) (Corvallis, Dept. of Food Science and Technology Oregon State Univ.) Food Technol. 28, H. 12, 106-108 (1969).

Für die amerikanische Konservenindustrie ist die Verwendung von Gefrierlachs von wachsendem Interesse. Die Verfasser stellen Untersuchungen darüber an, wie die bisher aufgetretenen Mängel, wie Fettoxydation, Gewebeveränderungen und Geleebildung vermieden werden können.

Die besten Ergebnisse sowohl nach der chemischen Analyse (Peroxidzahl) als auch nach der geschmacklichen Beurteilung (Ranzidität, Austrocknung und Verfärbung) wurden bei Vakuum verpackten Proben mit einer Zugabe von Antioxydantien BHA und BHT selbst nach einer Lagerungsdauer von 14 Monaten erhalten.

Als eine weitere wirksame Methode wird die Behandlung von gefrorenen Silberlachs-Steaks mit einer die Antioxydantien BHA, BHT sowie Natriumtriphosphat enthaltenden Stärkelösung durch Eintauchen beschrieben.

W. Schwabe (Bad Schwartau)

K. Priebe: Untersuchnngen zur Ursache und zur Vermeidung des Auftretens von Fadenziehen bei Bratheringsmarinaden. (Bremerhaven, Staatl. Veterinäramt.) Arch. Lebensmittel-Hyg. 21, 13-24 (1970).

Als Ursache des Fadenziehens von Bratmarinaden wurde Streptobacterium plantarum und in einem Fall Streptobacterium casei var. alactosus ermittelt. Diese Bakterien wurden dureh die zulässigen Konservierungsstoffkonzentrationen nicht gehemmt. Wirksam war jedoch eine 1 \%ige Essigsäurekonzentration. Zur Verhinderung des Fadenziehens bei Bratheringsmarinaden werden hygienische Maßnahmen, eine maximale Essigsäurekonzentration und eine Lagerungstemp. für das Fertigerzeugnis von $<10^{\circ} \mathrm{C}$ empfohlen.

J. Baumgart (Kiel)

\section{Sonstige Tierarten}

J. A. Liuzzo, S. C. Lagarde und A. F. Novak: Zur Nährstofizusammensetzung von bestrahlten, eisgelagerten Golfanstern. (Nutritive Composition of Irradiated Gulf Oysters Stored in Ice.) (Baton Rouge, Dept. of Food Science and Technol., Louisiana State Univ.) J. agric. Food Chem. 17, 764$766(1969)$.

Die Konservierung von Austern durch Bestrahlung war auf Grund früherer organoleptischer, chemischer und bakteriologischer Untersuchungen als praktikabel erschienen, wenn Strahlungsdosen von 0,2 Mrad zur Anwendung gelangten. Bei den Untersuchungen wurden frisch geöffnete Austern in drei Behandlungsgruppen unterteilt: A) Nicht bestrahlt, B) mit ${ }^{60} \mathrm{Co}$ mit $0,2 \mathrm{bzw}$. C) mit 0,4 Mrad bestrahlt; A) B) und C) wurden einen halben bzw. 10, 15 und 20 Tage auf Eis gelagert und dann auf ihren Gehalt an Wasser, Asche, Glykogen, Rohprotein, Nichtprotein-N, Protein, Rohfett und löslichen Zucker untersucht. - Unter den Nährstoffen hatte die Bestrahlung lediglich beim Rohprotein zu einer signifikanten Abnahme geführt, jedoch hob sich dieser Unterschied auf, wenn auf Protein umgerechnet wurde. Die Asche hatte mit zunehmender Lagerdauer signifikant abgenommen, der Glykogengehalt nahm im Gegensatz zum Gehalt an löslichem Zucker ab, jedoch nicht signifikant. Daß keiner der hier wesentlichen Năhrstoffe in beachtlichem Maße beeinflußt wurde, spricht verstärkt für die Möglichkeit einer Strahlenkonservierung von Austern.

G. Pfeiffer (Dachau) 